\title{
Organic Electroluminescent Devices Based on Polyurethane Derivatives Having Substituted Stilbene Pendants
}

\author{
Gỵu Hỵu Lee, Youngeup Jin, Sungeun Lee, Jong Gun Lee, Jin Young Kim, ${ }^{\dagger}$ Kwanghee Lee, \\ Sung-Ho Jin, ${ }^{\ddagger}$ Chang-Sik Ha, ${ }^{8}$ Mi-Sook Won, ${ }^{\#}$ Shin-Won Kang, and Hongsuk Suh \\ Department of Chemistry and Chemistry Institute for Functional Haterials, Pusan National Lniversity, Pusan 609-735, Korea \\ ${ }^{\dagger}$ Department of Physics, Pusan National Cniversitw, Pusan 609-735, Korea \\ $\ddagger$ Department of Chemistry Education, Ptisan National Linersity, Pusan 609-735, Korea \\ sDepartment of Polwmer Science \& Engineering, Pusan National Lniversitv, Pusan 609-735, Korea \\ "Korea Basic Science Institute, Pusan Branch, Pusan National Cniversity, Pusan 609-735, Korea \\ Received October 16, 2001
}

Keywords : Electroluminescence. Pendant. Polyurethane. Organic electroluminescence device.

There have been extensive research efforts on organic electroluminescent devices (OELDs) with the aim of application for the flat panel display (FPD). OELDs have also attracted much interest because of their particular low driving voltage. convenient design of the device structures. possible control of emission band, and low fabrication cost compared with any other devices. ${ }^{1.2}$ OELDs can be classified as either molecular or polymer-based. Molecular-based devices consist of vacuum deposited fluorescent enitter layers whereas polymer-based devices consist of either spinor dip-coated layers ${ }^{3.4}$ Most of the research in the field of polymer-based electroluminescent devices has focused on main-chain conducting polymers such as poly(plenylene vinylene) (PPV), poly ( $p$-phenylene) (PPP), their copolymers and soluble derivatives. ${ }^{5.6}$ Other groups have reported nonconjugated polymers with pendant chromophores for OELDs. ${ }^{7-10}$ The attachment of the fluorophore as the pendant group of a random-coil polymer presents several advantages: (I) the synthetic route would be simpler than that used for mainchain polymers; (2) the moderate solubility could be obtained by the nature of the backbone: (3) the enission wavelength would be easily controllable. We. recently reported the PU polymer with the 4-(dicyanomethylene)-2-methyl-6(4-dimethylaminostyryl)-4H-pyran (DCM) dye as the pendant. ${ }^{1 i}$ Even though it is known that the PU backbone have many quenching sites. the turn-on voltage of the PUDCM device was $c a .5 \mathrm{~V}$. Also. the change of the fluorophores in the side chain from para-cyanostilbene (PU-CN) to DCM (PU-DCM) caused the shift of PL emission wavelength. For the PL emission spectra of PU-CN and PUDCM. the maximum peaks were at $c a .520$ and $630 \mathrm{~mm}$. respectively: The maximum EL peaks of the PU-CN and PU-DCM devices were positioned at $c a .520$ and $630 \mathrm{~mm}$. respectively corresponding to the maximum PL peaks. Therefore. EL. and PL properties can be changed using different lumophore pendant groups possibly caused by the electron withdrawing effect of the DCM pendant. In the present work. PU derivatives with stilbene pendant containing one or two fluoro group were sy'nthesized. Also. one or two trifluoromethyl group were introduced on the stilbene side chain. OELDs using polyurethane derivatives with stil- bene pendants were fabricated to investigate the effect of the electron withdrawing substituents of the lumophore pendant on the EL and PL properties. Since PU derivatives possess different electron withdrawing substituents on the stilbene pendant, the shift of emission wave-length is expected.

\section{Experimental Section}

The overall pathway of the synthesis of the PU derivatives with substituted stilbene pendants is presented in Scheme 1 . In the first step. the hydroxy group of diethanolaniline 1 was protected by using acetic anhydride in pyridine. The aldehyde functional group was introduced at the port position by using $\mathrm{POCl}_{2}$ and DMF with acetyl-protected diethanolaniline. Deprotection of the acetyl groups by using aqueous $\mathrm{NaOH}$ solution provided the aldehyde $2^{\text {12a }}$ in $41 \%$ overall yield from 1 . The aldehyde 2 was coupled with the phosphonium salts 7-10 using t-BuOK/THF-EtOH solution

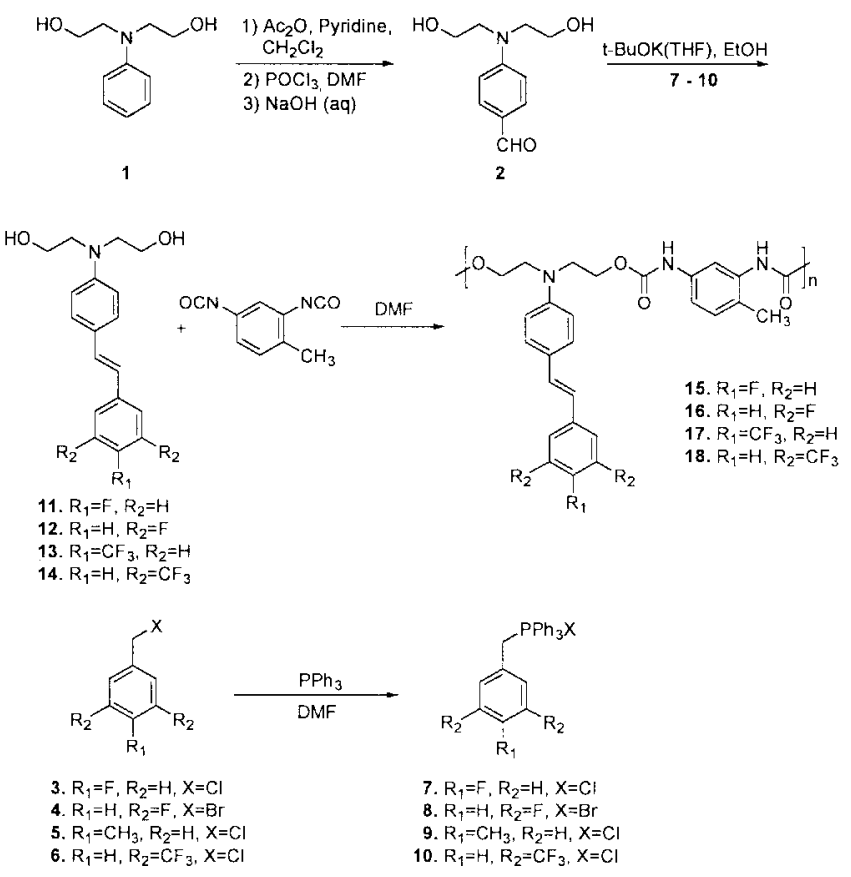

Scheme 1 
in $63-81 \%$ yields. The phosphonium salts $7-10$ were produced from the corresponding substituted benzylhalide 3-6 and triphenylphosphine in DMF in $95-98 \%$ yields. ${ }^{13}$ The polymerization of these monomers $11-14^{1 \text { |sb-e }}$ was achieved using toluene 2,4-diisocyanate (TDI) in DMF in 67-96\% yields. The number-average molecular weight $\left(\mathrm{M}_{\mathrm{n}}\right)$, weightaverage molecular weight $\left(\mathrm{M}_{\mathrm{w}}\right)$. and polydispersities of the resulting polymers. as determined by gel permission chromatography, were in the range of 3358-17010. 3377-41748. and $1.11-2.52$, respectively. The structures of the resulting polymers were identified by FT-IR spectroscopy with $\mathrm{KBr}$ pellets. The decomposition temperature $\left(T_{i}\right)$ was measured using the TGA under nitrogen atmosphere.

\section{Results and Discussion}

The comparison of the FT-IR spectrum of the polymers with those of the starting monomers showed a $\mathrm{C}=\mathrm{O}$ stretching vibration band at $1710 \mathrm{~cm}^{-1}$, which is characteristic of the urethane group and indicates the formation of urethane. The results of TGA reveals that polymers are quite stable. The polymers with stilbene chromophore exhibit onsets for degradation in the range of $225-280^{\circ} \mathrm{C}$. The DSC data of the glass transition temperature $\left(T_{g}\right)$ for the polymers was estimated at $150{ }^{\circ} \mathrm{C}$ and no melting point was detected, indicating that it represents a no crystalline phase. The DSC results show that these polymers possess high $T_{\mathrm{g}}$, which could be advantageous for the PLED device fabrication and helpful for the device longevity.

Inspection of the UV-vis absorption spectra of the monomers and polymers (Figure 1. 2) shows that the introduction of the electron withdrawing substituents at the stilbene is leading to the red shift.

The photoluminescence spectra (Figure 3,4) show the same tendency as compared to those of UV-vis spectra. The substitution with two fluoro groups at the stilbene generated red shift as compared to that of mono fluoro group. And the substitution with two trifluoromethyl groups also generated red shift as compared to that of mono trifluoromethyl group. Figure 5-7 show the current-voltage-electroluminescence characteristics measured from PU-F (15). PU-2F (16), and

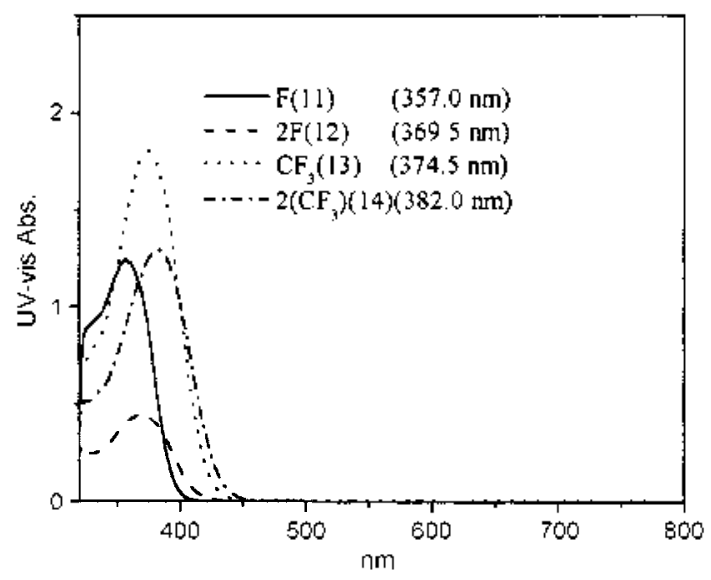

Figure 1. The UV-visible spectra of monomers.

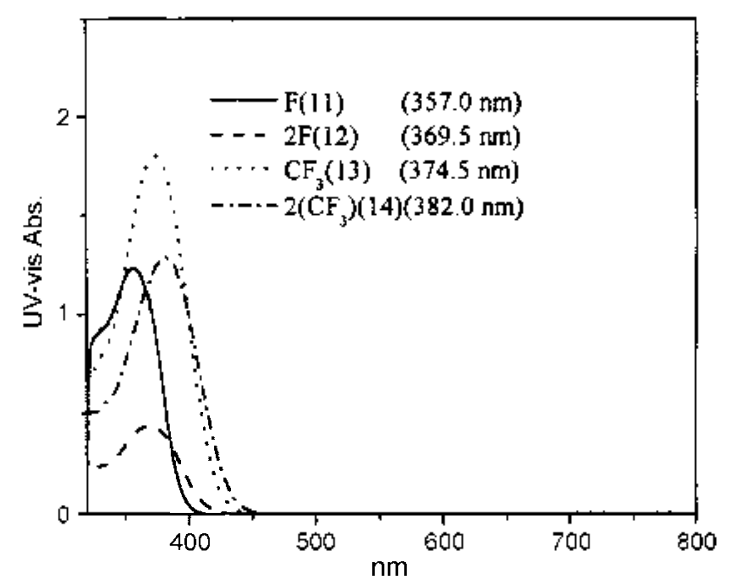

Figure 2. The UV-visible spectra of polymers.

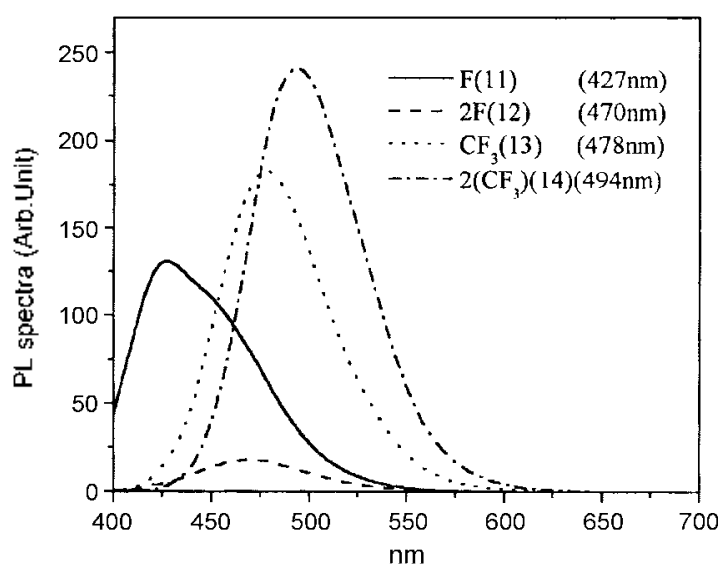

Figure 3. The PL spectra of monomers.

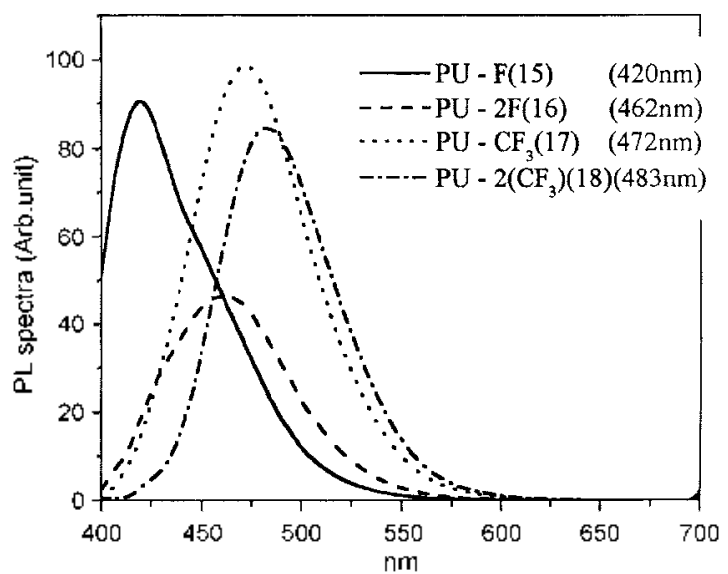

Figure 4 . The PL spectra of polymers.

$\mathrm{PU}-\mathrm{CF}_{3}$ (17). respectively. The fonvard bias current was obtained when the ITO is a positive electrode and $\mathrm{Al}$ electrode is negative. The forward current was increased with increasing fonvard bias voltage for all devices. The tum-on voltage of the PU-F (15) is higher than PU-2F (16).

In conclusion, it has been focused on the design and synthesis of the new polyurethane EL polymers with cluromophores in side chains. The stilbene cluromophores with electron withdrawing groups were synthesized in good 


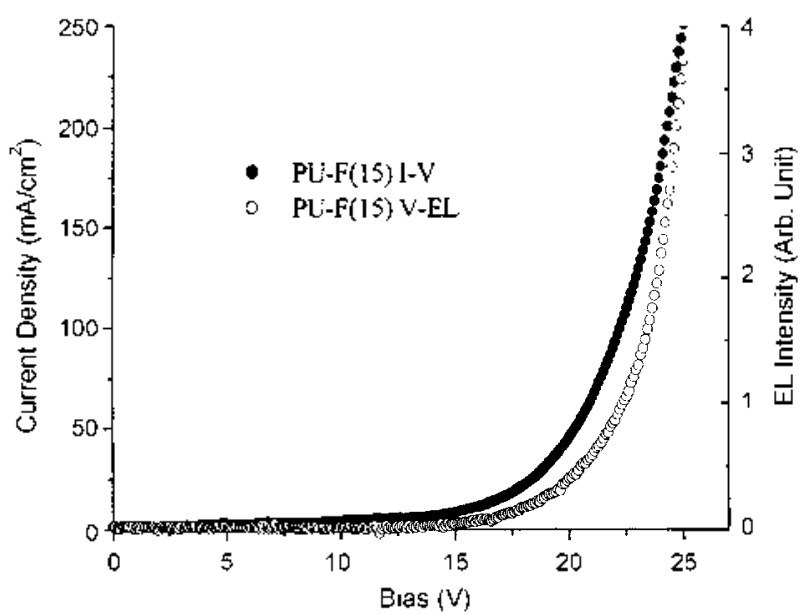

Figure 5. I-V-EL curves of PU-F.

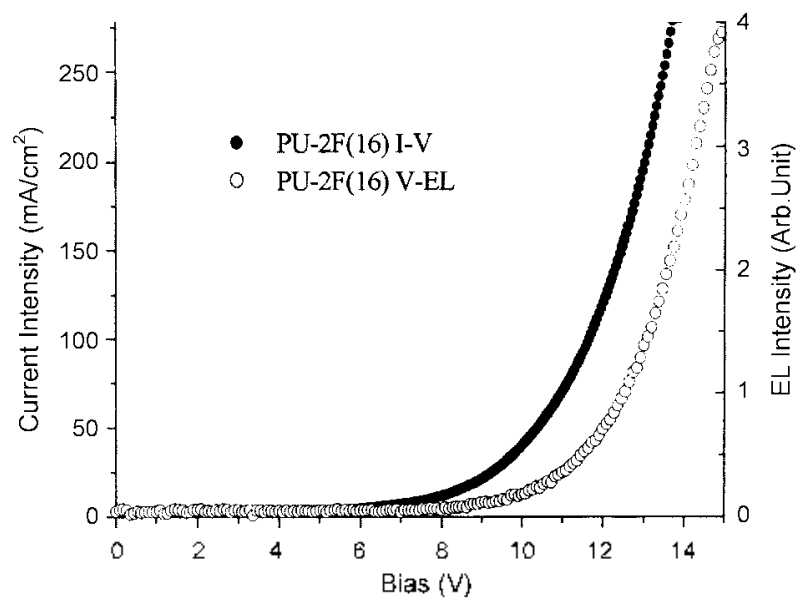

Figure 6. I-V-EL curves of PU-2F.

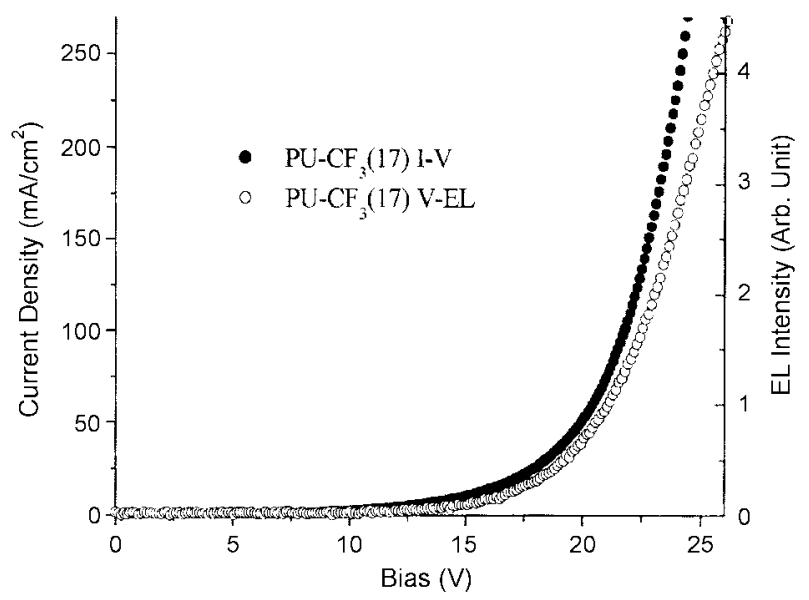

Figure 7. I-V-EL curves of $\mathrm{PU}-\mathrm{CF}_{3}$.

yields. Introduction of the electron withdrawing substituents at the stilbene side chain is leading to the red shift in UV-vis and PL spectra. OELDs using the new polyurethane (PU) derivatives with different lumophore pendants were fabricated. The current density $(J)$ voltage $(V)$ EL intensity $(L)$ of the OELDs were characterized.
Acknowledgment. This work was supported by Pusan National University Research Grant (H. Sulh. 1995-98)

\section{References}

1. Tang. C. W.: Van Slyke. S. A. Appl Phos Lett. 1982. 51.21.

2. Braun. D: Heeger. A. J. Appl. Pln's. Lett 1991, $58,1982$.

3. Tsutsui, T.: Aminaka E.: Hamada Y; Adachi. C.: Saito. S. Proc. SPIE 1993, 191. 180.

4. Gustaftsson. G.: Cao. Y.: Tracy. M.: Klavetter. F.: Colaneri. N.: Heeger. A. J. Kattue 1992. 375.477.

5. Burroughes. J. H.: Bradley. D. D. C.: Brown. A. R.: Marks. R. N.: Mackay. K.: Friend, R. H.: Burn, P. L.; Holmes, A. B. Natwe? 1990. 347,539

6. Grem. G.; Leditzky, G.: Ullrich. B.; Leising. G. Ad. Hater 1992. t. 32.

7. Patel. H.: Patel. S. J. Hachonol. Sci. Chen 1984. A21. 343.

8. Yen. T.: Devar. M.: Rembaum. A. J. Macroniol Sci. Chent 1970. 4. 693 .

9. Abyshev. A.: Brodskii, Y.: Denisenko, P; Kropachev. V; Melnik, Y.: Saveleva. N.; Simonova, I. Khin. Fam. 2h. 1977. 11,41.

10. Chent. Y. J. Polm Res. 1994. 1. 285

11. Lim. H.: Noh. T. Y.: Lee. G. H.: Lee. S. E.: Jeong. H.: Lee. K. Cha. M.: Suh. H.: Ha. C.-S. Thin Solid Fints 2000. 363. 152.

12. (a) 4-[Bis-(2-hydroxyethyl)amino]benzaldehyde (2). Rf 0.18 ( $\mathrm{SiO}$. $75^{\circ}$ \% EtOAc-hexane): ${ }^{\mathrm{H}} \mathrm{H}-\mathrm{NMR}\left(200 \mathrm{MHz} \cdot \mathrm{CDCl}_{3}\right) \delta$ (ppm) $3.67(\mathrm{t} .4 \mathrm{H}, J=4.7 \mathrm{~Hz}), 3.83$ (t. $4 \mathrm{H} . J=4.7 \mathrm{~Hz}) .6 .69(\mathrm{~d}$. $2 \mathrm{H} . J=8.9 \mathrm{~Hz}$ ). 7.64 (d. $2 \mathrm{H} . J=8.9 \mathrm{~Hz}) .9 .63\left(\mathrm{~s} .1 \mathrm{H}\right.$ ). ${ }^{13} \mathrm{C}-\mathrm{NMR}$ $\left(50 \mathrm{MHz} . \mathrm{CDCl}_{3}\right) \delta(\mathrm{ppm})$ 59.2. 62.3. 113.6. 126.2. 130.6. 150.3. 1900. HRMS (EI). $n z 209.1057$ (calculated for $\mathrm{C}_{11} \mathrm{H}_{1} \leqslant \mathrm{NO}_{3}$ 209.1053). (b) 2-[ [4-[2-(4-Fluoropheny) vinyl]phenyl\} (2-hy droxyethyl amino]ethanol (11). ${ }^{1} \mathrm{H}-\mathrm{NMR}(200 \mathrm{MHz}$. DMSO-d $) \delta$ (ppm) $3.66(\mathrm{t}, 4 \mathrm{H}, J=5.5 \mathrm{~Hz}) .3 .83$ (t. $4 \mathrm{H} . J=5.5 \mathrm{~Hz}$ ), 4.90 (s. $2 \mathrm{H}$ ). 6.64 (d. $2 \mathrm{H} . J=8.7 \mathrm{~Hz}$ ). 6.87 (d. $1 \mathrm{H} . J=16.5 \mathrm{~Hz}$ ). 7.01 (d. IH. $J=16.5 \mathrm{~Hz}$ ). $7.1 \mathrm{l}$ (t. $2 \mathrm{H} . J=8.8 \mathrm{~Hz}) .7 .34$ (d. $2 \mathrm{H} . J=8.7 \mathrm{~Hz}$ ). 7.51 (dd. $2 \mathrm{H} . J=5.9 .8 .8 \mathrm{~Hz}$ ). ${ }^{13} \mathrm{C}-\mathrm{NMR}(50 \mathrm{MHz}$. DMSO-d $) \delta$ (ppm) 52.4, 60.1. 112.6. 115.6, 123.3. 125.7. 127.7, 128.3, 130.1. $134.2,147.5(\mathrm{~d} . J=25.5 \mathrm{~Hz}), 161.6(\mathrm{dd}, J=244.5 .13 .62 \mathrm{~Hz})$. HRMS (EI). $m z$ z01.1483 (caleulated for $\mathrm{C}_{18} \mathrm{H}_{20} \mathrm{FNO}_{2} 301.1479$ ). (c) 2-[\{4-[2-(3.5-Difluorophenyl) vinyl] phenyl\}-(2-hydroxyethyl)amino] ethanol (12). 'H-NMR (200 MHz. acetone-d $\left.{ }_{6}\right) \delta$ (ppm) 3.60 (t. $4 \mathrm{H} . J=5.5 \mathrm{~Hz}) .3 .77$ (q. $4 \mathrm{H} . J=5.5 \mathrm{~Hz}) .4 .20(\mathrm{t}$. $2 \mathrm{H} . J=5.5 \mathrm{~Hz}) .6 .76(\mathrm{~d} .2 \mathrm{H} . J=8.8 \mathrm{~Hz}) .6 .83(\mathrm{dd}, 1 \mathrm{H}, J=2.6$. $9.16 \mathrm{~Hz}$ ) 6.95 (d, $1 \mathrm{H} . J=16.5 \mathrm{~Hz}), 7.16$ (dd. $2 \mathrm{H}, J=2.2 .9 .16$ $\mathrm{Hz}) .7 .26(\mathrm{~d} .1 \mathrm{H} . J=16.5 \mathrm{~Hz}), 7.43(\mathrm{~d}, 2 \mathrm{H}, d=8.8 \mathrm{~Hz}) .{ }^{13} \mathrm{C} \cdot \mathrm{NMR}$ (50 MHz. acetone-d $\left.d_{f}\right) \delta(\mathrm{ppm}) 54.3 .59 .5 .101 .15(\mathrm{t} . J=25.5 \mathrm{~Hz})$. 108.4 (d. $J=24.6 \mathrm{~Hz}) .112 .1$. 121.2. 124.2. 128.3. 132.1. 142.8 . 148.8. 163.54 (dd. $J=243.8 .13 .7 \mathrm{~Hz}$ ). HRMS (EI). $n z 319.1392$ (calculated for $\left.\mathrm{C}_{13} \mathrm{H}_{19} \mathrm{~F}_{2} \mathrm{NO}_{2} 319.1385\right)$. (d) $2-[(2-\mathrm{Hydroxyethy1})$ \{4-[2-(4-trifluoromethylpheny) vinyl]pheny1\}-(2-hydrosyethyl)amino]ethanol (13). ${ }^{\text {H }} \mathrm{H}-\mathrm{NMR}(200 \mathrm{MHz}, \mathrm{DMSO}-\mathrm{d}$ ) $\delta$ (ppm) 3.66 (t. $4 \mathrm{H} . J=5.5 \mathrm{~Hz}$ ). 3.83 (t. $4 \mathrm{H} . J=5.5 \mathrm{~Hz}$ ). 4.92 (s. $2 \mathrm{H}) .6 .66$ (d. $2 \mathrm{H} . J=8.4 \mathrm{~Hz}$ ). 6.96 (d. IH. $J=16.2 \mathrm{~Hz}$ ). 7.23 (d. 1H. $J=16.2$ $\mathrm{Hz}) .7 .40$ (d. $2 \mathrm{H} . J=8.4 \mathrm{~Hz}$ ). 7.60 (d. $2 \mathrm{H} . J=8.1 \mathrm{~Hz}) 7.67$ (d. $2 \mathrm{H}$. $J=8.1 \mathrm{~Hz}$ ) ${ }^{13} \mathrm{C}-\mathrm{NMR}(50 \mathrm{MHz}$. DMSO-d $) \delta(\mathrm{ppm}) 52.6 .60 .2$. $112.4,118.7,119.0,120.9,124.2 .125 .7,128.4,130.0 .132 .7$ (q. $J$ $=33 \mathrm{~Hz}), 138.2 .143 .7$, HRMS (EI) $. m / 2351.1446$ (calculated for $\mathrm{C}_{1} \mathrm{H}_{2(1} \mathrm{F}_{3} \mathrm{NO}_{2}$ 351.1447). (e) 2-[\{4-[2-(3.5-Bistrifluoromethyl)phenyl) winyl] phenyli - (2-hydroxyethyl)amino]ethanol (14). ${ }^{1} \mathrm{H}-\mathrm{NMR}(200 \mathrm{MHz}$. acetone-dib) $\delta(\mathrm{ppm}) 3.6 \mathrm{l}(\mathrm{t} .4 \mathrm{H} . J=5.5 \mathrm{~Hz})$. $3.78(\mathrm{q} .4 \mathrm{H}, J=5.5 \mathrm{~Hz}), 4.23(\mathrm{t}, 2 \mathrm{H} . J=5.5 \mathrm{~Hz}) .6 .79(\mathrm{~d} .2 \mathrm{H}, J=$ $9.1 \mathrm{~Hz}) 7.15$ (d. $1 \mathrm{H}, J=16.1) .7 .49(\mathrm{~d}, 1 \mathrm{H} . J=16.1 \mathrm{~Hz}) .7 .49(\mathrm{~d}$, $2 \mathrm{H}, J=9.1 \mathrm{~Hz}), 7.77(\mathrm{~s}, \mathrm{lH}) .8 .12(\mathrm{~s} .2 \mathrm{H}),{ }^{1} \mathrm{C} . \mathrm{NMR}(50 \mathrm{MHz}$. acetone-d $\mathrm{d}_{\text {) }} \delta(\mathrm{ppm})$ 54.2. 59.5. 112.0. 118.9. 119.0. 120.1. 124.1. 125.7. 128.5 .131 .5 (q. $J=32.8 \mathrm{~Hz}) \cdot 133.3 .141 .5 .149 .0$. HRMS (EI) $m z 419.1317$ (calculated for $\mathrm{C}_{20} \mathrm{H}_{14} \mathrm{~F}_{2 \mathrm{NO}} 419.132 \mathrm{I}$ ).

13. Jung. M. E.; Lam, P. Y. S.; Mansuri, M. M.: Speltz, L. M. J. Org Chem. 1985, 50(7). 1987. 